\title{
APRENDENDO A DANÇAR
}

EPALANGA, Kalaf. Também os brancos sabem dançar - um romance musical. São Paulo: Todavia, 2018. 304 p.

Kalaf Epalanga nasceu em Angola, em 1978, e vive em Portugal desde os anos 1990. Músico, integrou a banda Buraka Som Sistema, uma das principais difusoras mundiais do kuduro, gênero de música dançante inventada nos bairros desassistidos de Luanda. Escritor, colabora na imprensa de Lisboa e publicou duas coletâneas de crônicas, Estórias de amor para meninos de cor (2011) e $O$ angolano que comprou Lisboa (por metade do preço) (2014). Este seu primeiro romance mistura, de modo interessante e surpreendente, elementos autobiográficos, narrativas ficcionais e reflexões do autor (ou pertenceriam elas a seus diversos personagens?).

O livro se divide em três partes. A parte I faz pensar não num romance, mas numa autobiografia musical e reflexiva, à maneira do Verdade tropical, de Caetano Veloso (tendo em comum com este, como veremos, a centralidade do tema do encarceramento). Traz narrativa em primeira pessoa, e narrador em tudo semelhante ao autor - pelo menos, com base no que deste se pode saber pela orelha do livro, e pelas suas entrevistas disponíveis na internet. $\mathrm{Na}$ p. 53, descobrimos que o personagem-narrador, tal como o autor, se chama Kalaf. "Kalaf”, ao contrário do que se poderia pensar, não é um nome "angolano”, nem é comum entre falantes de quicongo ou umbundo; é o nome de um cantor de merengue dominicano, Luis Kalaff, e também o nome oculto do "Príncipe Desconhecido" da ópera 
Turandot, de Puccini. A segunda e a terceira partes do livro não são, porém, narradas por Kalaf - e essa mudança de perspectiva é um belo achado do livro. O personagem "Kalaf” se torna coadjuvante nas partes II e III; em meio aos novos narradores, com suas aventuras e amores, as reflexões do autor Kalaf prosseguem e se aprofundam.

As reflexões giram em torno de música e dança em Angola e na comunidade africana de Lisboa; de cosmopolitismo e de imigração; de colonialismo, de fronteiras; e de como se livrar delas (de fato, o romance fala mais sobre livrar-se de fronteiras do que sobre livrar-se de colonialismo. Fica a sugestão). Acho insatisfatória a adesão manifestada aqui e ali a uma suposta "música de dança global” (p. 81 e outras), mas deixo passar, pois afinal é de um romance que se trata.

O ponto de partida do livro é a detenção de Kalaf pela polícia norueguesa, pouco depois de entrar no país, vindo da Suécia em direção a Oslo. Em agosto de 2008 ele se dirigia, em ônibus de linha, para a capital norueguesa, para se apresentar naquela noite, com o Buraka Som Sistema, em um dos mais importantes festivais de música dançante eletrônica da Escandinávia. A detenção ocorre por falta de passaporte válido. Mesmo vivendo em Lisboa desde muitos anos, Kalaf não era ainda cidadão europeu, e perdera dias antes, num hotel de Paris, seu passaporte angolano com o devido visto português. Sem passaporte, não podia ir de avião, daí o recurso ao ônibus, na vã esperança de não ser interpelado no trajeto. Depois do episódio, Kalaf decide aceitar a oferta de uma amiga portuguesa para com ela celebrar o chamado - ironicamente - "casamento branco", com o estrito objetivo de obter a nacionalidade portuguesa, e o respectivo direito de circular livremente na Comunidade Europeia. Mas isso, não sabemos se ocorreu só com o personagem, ou se também com o autor...

Enquanto é conduzido pelos policiais à delegacia, ao interrogatório e finalmente a uma cela, o autor-personagem repassa com o leitor sua trajetória vivida de Angola para Lisboa, e nesta, para a profissionalização e sucesso musicais que estão a ponto de levá-lo ao palco do importante festival. Ao fazê-lo, traça um instrutivo panorama da música popular angolana, 
com destaque para gêneros festivos e dançantes pouco ou nada conhecidos no Brasil, como o semba, a kizomba, a tarraxinha... e a estrela principal: o kuduro.

O nome kuduro, como se sabe, vem da cena de dança desajeitada de Jean-Claude Van Damme no filme Kickboxer: o desafio do dragão (1989). Os quadris imóveis do astro lutador teriam inspirado o músico Tony Amado a produzir em Luanda, com sintetizador e bateria eletrônica, “Amba kuduro”, sucesso seminal dançado nos subúrbios da cidade com uma mistura do break norte-americano e o ndombolo do Congo. Ao longo dos anos 1990, o kuduro se consagrou como um dos principais ícones musicais de Angola, com projeção internacional a partir dos anos 2000. O primeiro sucesso do Buraka Som Sistema, "Yah", é de 2007. O nome da banda não é angolano, mas uma referência à diáspora africana em Lisboa: Buraca foi uma das freguesias (extinta em 2013) de Amadora, cidade da região metropolitana de Lisboa com grande presença de imigrantes do continente.

O livro também deixa entrever um pouco da sofrida história política de Angola desde os anos 1980, sobre a qual até mesmo o público com formação universitária conhece tão pouco no Brasil. Esta se entrelaça com a história musical e dançante daquele país, o que é comum; menos comum é que tal entrelaçamento seja abordado tão explicitamente. Quem se interessa pela África contemporânea pode saber o básico: luta anticolonial protagonizada pelo Movimento Popular pela Libertação de Angola (MPLA - o "Emepéla” que, rimando com "canela”, conclui a música "Morena de Angola”, de Chico Buarque); sua chegada ao poder em 1975, sob liderança do (também) poeta Agostinho Neto; a guerra civil com a União Nacional para a Independência Total de Angola (UNITA), liderada por Jonas Savimbi, que só se conclui definitivamente com a morte deste em 2002.

O livro percorre caminhos menos básicos. No século XXI, o sobrinho de Agostinho Neto, o dr. Eugênio Neto, é um "empresário ligado à banca e aos diamantes” (lembremos que Angola é um dos maiores produtores mundiais de diamantes) e apaixonado por música (p. 43). Personagem do livro, o dr. Eugênio Neto propõe comprar 
o selo fonográfico de Kalaf e seus amigos - recebendo uma altiva recusa do protagonista-autor. No encontro entre Kalaf e Eugênio, o que se diz deste último, ou o que ele mesmo diz de si, coincide em grande parte com a apresentação do Eugênio real, no site de uma das empresas reais em que trabalha, EDreamsTec, com sede em Luanda, e com objetivos que incluem “desenvolver [...] operações nos países [africanos] através da captação de investimento para apoiar a industrialização". ${ }^{1}$ Lemos no referido site:

Eugénio Neto, 54 anos, nasceu em Luanda. Esteve no primeiro grupo de estudantes que partiu para a ex-União Soviética em 1976. Licenciou-se em Medicina, pelo Instituto Estatal de Medicina Piragova de Moscovo. O curso demorou seis anos já que o primeiro foi dedicado ao domínio da língua. "Quando cheguei a Moscovo [Moscou] só sabia dizer três palavras em russo", recorda.

No livro, porém, se lê:

[Viajou com o] primeiro grupo de estudantes angolanos para as universidades da antiga União Soviética, em 1976. Foi lá que se licenciou em medicina, pelo

1 EdreamsTec $飞$.
Instituto Estatal de Medicina Piragova de Moscou, num curso que durou seis longos invernos. O primeiro ano foi dedicado ao domínio da língua, contou-me. "Quando cheguei a Moscou só sabia dizer três palavras em russo" (pp. 43-44).

\section{Continua o site:}

O empresário confessa que a sua ligação à música e à produção de espectáculos começou em Benguela, em 1972 e 1973, quando era responsável pela área da cultura. “Os géneros iam desde o semba e a rumba até à música de intervenção. Trouxemos pela primeira vez o Bonga a Angola”, recorda.

No livro, por outro lado, encontramos:

Era sobejamente conhecido seu amor pela música, uma relação que começou ainda no tempo colonial, e justamente na minha [de Kalaf] Benguela umbilical, nos idos de 1972 ou 1973, onde se promoviam encontros musicais nos quais o semba e a rumba predominavam. "Trouxemos pela primeira vez o Bonga a Angola”, disse-me orgulhoso.” (p. 43).

Bonga - esclareça-se para nós, brasileiros, tão ignorantes sobre música angolana - é um dos grandes 
cantores e letristas angolanos dos anos 1970 e 1980. Ele vivia na Europa desde os anos 1960, daí a referência a “trazê-lo a Angola”.

A vida imita a arte, a arte imita a vida. Personagens empresariais, políticos e musicais, como o "Eugênio Neto" do livro (e o do site, sem as aspas), podem imitar a si mesmos com inimitável proficiência. Em todo caso, conforme o livro avança, Kalaf, o autor, vai tomando distância de suas experiências mais diretas. Kalaf, o personagem, é um homem negro que diz dançar mal; a narradora da parte II de seu livro é uma mulher branca, professora de danças africanas.

Ao escrever esta resenha, fiquei na dúvida se devia revelar ao leitor que as partes II e III do livro não são narradas por Kalaf, e se distanciam da chamada "autoficção". A surpresa que tive ao constatá-lo foi prazerosa; anunciá-lo seria um tipo de spoiler? Creio que não. Achei estimulante a entrada da nova narradora no início da parte II, trazendo tom de romance ao que se aproximava, perigosamente, da autobiografia precoce; até então, imaginava que o livro continuaria na mesma toada autoficcional por mais duzentas páginas - perspectiva que começava a me assustar. Penso fazer um favor à recepção do livro, avisando seus possíveis leitores de que tal não é o caso.

Pois bem, Sofia, a professora de kizomba e outras danças africanas, é filha de uma angolana branca que, ainda adolescente, teve que sair do país em 1975 com seus pais portugueses, devido à nova situação política. A mãe de Sofia, em Portugal, depois de casar-se, de dar à luz, e de separar-se do primeiro marido, apaixonou-se por um angolano negro que, tendo saído do país natal com uma bolsa para estudar na Alemanha Oriental, acabou ficando na Europa. Sofia fala do padrasto: "Ele é negro, pele de chocolate noventa e cinco por cento de cacau, cabelo carapinha. Eu, igual à minha mãe. Branca, olhos azuis, cabelo louro. Pela aparência, não podíamos ser mais diferentes. Mas na alma respiramos e sentimos a música exatamente da mesma forma. Ele ensinou-me tudo o que sei sobre esta dança” (p.123). Também os brancos sabem dançar, quando aprendem.

O narrador da parte III do livro se distancia ainda mais do universo familiar a Kalaf, nosso autor-personagem. Trata-se do próprio policial 
norueguês que o detém para averiguações na entrada do país, e que na parte I do livro é referido como "o viking”. Um policial que se questiona sobre sua escolha profissional, e cujos relatórios revelam uma vocação oculta: "Devias escrever romances policiais, e não relatórios de polícia”, lhe diz o inspetor (p. 222). Dubitativo, quase hamletiano, repete para si mesmo que nunca matou ninguém, nem ao menos disparou jamais com sua arma de serviço, e nem sequer conhece quem tenha matado. Mais ainda, nos informa, para perplexidade de seus leitores brasileiros, que "em 2007 não se disparou um único tiro" (p. 221), embora não fique claro se fala da polícia norueguesa como um todo, ou se apenas do setor em que trabalha.

Seu avô e seu pai também foram policiais: "Meu avô dizia que a arma mais poderosa que a polícia carrega é a massa cinzenta” (p. 221). Mais perplexidade do lado de cá... Porém, este avô não queria que ele seguisse a mesma carreira - e quem lhe conta isso é Ava, uma imigrante libanesa que foi sua paixão de adolescência, e que reencontra justamente ao voltar à pequena cidade natal, por ocasião do funeral do avô. Através de Ava também ficamos sabendo algo sobre a cena musical de Beirute, assim como ficamos sabendo sobre a cena musical norueguesa através de Nygard, o policial-narrador, e de sua colega de trabalho e confidente, Mari Gunnhild, cujo pai, também policial, mas sueco, prendeu Jimi Hendrix em Gotemburgo, em 1968, prisão que de fato aconteceu naquele ano, depois que o guitarrista depredou o quarto do hotel em que estava.

(Confesso que apesar de meu interesse profissional e artístico pela diversidade musical do mundo, a mim incomoda um pouco, no romance, o recurso a listas desenfreadas de nomes de álbuns e de bandas norte-americanas, angolanas, portuguesas, norueguesas, libanesas...)

As dúvidas de Nygard são exasperadas por seu envolvimento involuntário com a morte de uma imigrante africana de religião muçulmana, Kedijah. A menina tinha 16 anos, estava grávida e preferiu se matar na prisão a ser enviada de volta à Eritreia. Ao saber disso, Nygard, que a interrogara, se sente culpado, embora tenha agido com ela dentro das normas: "Fizemos o que nos é ordenado. Se não apresentarem documentos, enviamos 
para o centro de detenção, nada de estranhar” (p. 199). Deprimido, tira uma licença do serviço, mas começa a sonhar com Kedijah e com a canção que ela cantava em sua língua nativa, enquanto esperava seu destino na delegacia (p. 199).

A parte I e a parte III se encontram no final do livro, tendo a parte II como um intermezzo romântico em torno da dançarina loura de kizomba e de seu envolvimento com um brasileiro de passagem na cidade, a quem ela apresenta a noite musical de Lisboa.

Ler um autor angolano tem para nós, brasileiros, entre outras qualidades, a de proporcionar um contato com riquezas desconhecidas da língua portuguesa. Será que poderemos um dia pensar em tais riquezas como um patrimônio linguístico comum, também nosso, dos brasileiros? Afinal, em português de Angola - e, presume-se, também no de Portugal - temos o direito de usar, sem pedantismo, expressões como "não vá alguma palavra escapar-se-nos” (p. 217)! O entusiasmo não é pela combinação de pronomes: é por ela passar com naturalidade na leitura, quase despercebida. Era bom, então, que palavra ou expressão alguma não se nos escapasse: palavras e expressões angolanas, como "Loico de bater funge", apetrecho culinário; "Musseques”, bairros informais, favelas; "Catana”, facão; "Monangambé”, trabalhador contratado em condições precárias, bóia-fria; "Candengue”, criança; “Cacimbo”, estação seca, estiagem; "Bangão”, vaidoso; "Candongueiro”, transporte informal. E que não se nos escapassem, tampouco, palavras e expressões portuguesas, como "Garina”, garota; "Conversa de chacha”, conversa fiada; "Berma”, acostamento; "De malas aviadas", de malas prontas; "Boelo”, pessoa sem-noção; "Piropo", cantada, paquera; “Foleiro”, brega, e por aí vai...

Para aproveitar essa riqueza toda, nós leitores brasileiros bem merecíamos mais notas de rodapé, ou talvez ainda melhor, um glossário no final do livro. Em vez disso, a edição brasileira só traz notas de rodapé para três palavras: "Esquadra”, que é delegacia; "Kota”, que é pessoa mais velha, coroa; e "Betinho”, que é mauricinho.

No cômputo geral, a autoficção é amplamente suplantada pela aloficção, e todos saem ganhando. Também os brancos sabem dançar é uma leitura 
prazerosa e instrutiva, portadora de perspectiva original sobre fluxos globais contemporâneos, com destaque para a música e a dança.

\section{Carlos Sandroni (DD}

Universidade Federal de Pernambuco

doi: 10.9771/aa.v0i63.44060 